\title{
Finding the Calm in the Chaos: An Institutional Protocol for Anesthetic Management of a Patient for Neurosurgery during Coronavirus Disease 2019 Pandemic
}

\author{
Aishvarya Shree Nedunchezhian ${ }^{1}$ Neeraja Ajayan ${ }^{1}$ Ajay Prasad Hrishi P. ${ }^{1} \quad$ Unnikrishnan Prathapadas ${ }^{1}$ \\ Manikandan Sethuraman ${ }^{1}$ Thomas Koshy ${ }^{1}$ \\ ${ }^{1}$ Division of Neuroanesthesia, Department of Anesthesiology, \\ Sree Chitra Tirunal Institute for Medical Sciences and Technology, \\ Trivandrum, India

\begin{abstract}
Address for correspondence Ajay Prasad Hrishi P., MD, DM, MNAMS, MIMSA, Division of Neuroanesthesia, Department of Anesthesiology, Sree Chitra Tirunal Institute for Medical Sciences and Technology, 4th Floor, C Block, Trivandrum-695011, India (e-mail: drajay@sctimst.ac.in).
\end{abstract}

\begin{abstract}
Keywords

- COVID-19

- neuroanesthesia

- risk stratification

- personal protective equipment

“Coronavirus disease 2019" (COVID-19) transmitted by a novel coronavirus via contact or droplet spread is a highly infectious disease, the containment of which requires vigilance and stringent infection control policies. In the backdrop of hospitals becoming hot zones and an increasing number of health care workers contracting the disease, it is crucial to formulate an approach while administering anesthesia during the testing times of COVID-19 pandemic. In this background, this comprehensive article deals with the perioperative management during this pandemic and includes risk stratification based on an innovative simple scoring system, rationale use of personal protective equipments, and infection prevention protocols. The document of updated literature, though not intended to replace any guidelines, is aimed at providing protocol to health care workers to protect themselves while providing the best care in this pandemic.
\end{abstract}

\section{Introduction}

"Coronavirus disease 2019" (COVID-19) transmitted by a novel coronavirus via contact or droplet spread is a highly infectious disease, the containment of which requires vigilance and stringent infection control policies. ${ }^{1}$ In the backdrop of hospitals becoming hot zones and an increasing number of health care workers (HCW) contracting the disease, it is crucial to formulate an approach while administering anesthesia during the testing times of COVID-19 pandemic.,3 While operating theaters become overtly strained due to the limited resources and exposure of staff to high-risk activities such as airway management, it is imperative to avoid practices which are not evidence based and to place efforts with sufficient knowledge and expertise. ${ }^{2-4}$

In the face of this highly infectious disease, this article aims to address critical issues pertinent to anesthetic practice and concisely brings together recommendations for anesthetic management of COVID-19 from existing literature and protocol followed at our institution. This can be adapted to support individual, complex, and exceptional circumstances based on the attending anesthesiologists' professional judgement.

The anesthetic management has been discussed in the following subheadings:

A. Preanesthesia consultation

B. High-risk procedures for aerosolization and droplet transmission

C. Preparing the operation theater (OT)

D. Guidelines for rationale use of personal protective equipment's (PPE)

E. Transfer of patients into OT

F. Anesthetic management

G. Decontamination of OT 


\section{Preanesthetic Consultation}

1. All patients should be screened at the outpatient clinic entrance as per the government checklist and any doubtful case should be referred to the COVID-19 clinic., ${ }^{5,6}$

2. In a region where community transmission is proven or anticipated, any patient entering the preanesthetic clinic-even if they are asymptomatic-should be considered as a suspect case of COVID-19. ${ }^{5}$

3. Telemedicine as a preanesthetic tool has been validated and is an effective and safe method of assessing patients during this crisis. Whenever possible preadmission anesthesia consultation using video conferencing has to be encouraged. ${ }^{5,7}$

4. Restricting the number of people accompanying these patients to a minimum can prevent crowding and make social distancing easier.

5. The anesthesiologist should wear PPE at all times in the clinic and practice hand hygiene every time he comes in contact with the patient. ${ }^{5}$

6. A comprehensive screening tool has been developed by our department to assess the risk grading of the patients to categorize these patients into high, intermediate, and low risk (-Table 1).

7. The reusable medical equipment in the PAC clinic, such as the stethoscope and the blood pressure apparatus, must be sanitized frequently. Every day, after the preanesthesia consultations, the room should be cleaned and disinfected..$^{5}$

8. Since patients are suspects of COVID-19 infection, they should be clearly explained about the droplet and airborne precautions that will be taken by the HCW. Informed consent for the same needs to be taken.

\section{High-Risk Procedures for Aerosolization and Droplet Transmission in the Perioperative Period}

Aerosols are generated when an air current moves across the surface of a liquid film. Personnel involved in aerosol-generating procedures (AGP) like anesthesiologist, medical/Nursing/paramedical personnel performing, or assisting AGPs are defined as category A HCWs.

Bag mask ventilation, intubation, tracheostomy, extubation, bronchoscopy, nebulization, noninvasive ventilation, chest physiotherapy, coughing/vomiting, bone drilling, laparoscopic, and endoscopic procedures, cavitron ultrasonic surgical aspirator, and craniotomy are some examples of AGP., 5 Procedures like invasive line placements, bladder catheterization, regional nerve blocks, lumbar puncture, muscle biopsy, and transthoracic echocardiography are nonaerosol generating.

\section{Preparation of the Operation Theater}

1. Dedicated OT with signage "COVID-19 operation theatre" should be posted on the doors to minimize staff exposure. ${ }^{5,6}$

2. This theater should ideally be the one which is closest to the COVID-19 intensive care unit (ICU) to facilitate the transfer of patients and should also be the one which avoids OT traffic.
Table 1 Checklist for use by category a health care worker prior to intervention in patients in operation theater

\begin{tabular}{|c|c|c|}
\hline No. & $\begin{array}{l}\text { Exposure (exposure for any close family } \\
\text { members also for point } 1-5 \text { ) }\end{array}$ & $\begin{array}{l}\text { Points } \\
\text { if yes }\end{array}$ \\
\hline 1 & $\begin{array}{l}\text { Any history of travel within the prior } 14 \text { days to } \\
\text { a location where there is local or community } \\
\text { transmission of COVID-19? }\end{array}$ & 6 \\
\hline 2 & $\begin{array}{l}\text { Any history of close contact }{ }^{1} \text { with a confirmed } \\
\text { or suspected case of COVID- } 19 \text { in the prior } \\
14 \text { days at home or at work including in health } \\
\text { care settings? }\end{array}$ & 6 \\
\hline 3 & $\begin{array}{l}\text { Is he/she living in the same household or flat } \\
\text { as of a person with symptomatic laboratory- } \\
\text { confirmed COVID-19 infection? }\end{array}$ & 6 \\
\hline 4 & $\begin{array}{l}\text { Is there any history of traveling in close proxim- } \\
\text { ity with (that is, within } 1 \mathrm{~m} \text { separation from) a } \\
\text { COVID- } 19 \text { patient in any mode of travel? }\end{array}$ & 6 \\
\hline 5 & $\begin{array}{l}\text { Is there any history of severe acute respiratory } \\
\text { illness in the absence of an alternative diagnosis } \\
\text { that fully explains the clinical presentation? }\end{array}$ & 6 \\
\hline 6 & $\begin{array}{l}\text { Critically ill patient with unexplained pneumonia } \\
\text { or respiratory failure }\end{array}$ & 6 \\
\hline 7 & $\begin{array}{l}\text { Health care worker managing a patient with } \\
\text { acute respiratory symptom or fever in the last } \\
14 \text { days }\end{array}$ & 6 \\
\hline 8 & $\begin{array}{l}\text { Are you a health care worker/public health } \\
\text { official/social leader? }\end{array}$ & 4 \\
\hline 9 & History of fever/ LRI/ diarrhea in last 14 days & 4 \\
\hline 10 & $\begin{array}{l}\text { Critically ill patient (patients requiring ICU man- } \\
\text { agement like sepsis, multiorgan dysfunction, life } \\
\text { threatening malignancy, etc.) }\end{array}$ & 2 \\
\hline 11 & $\begin{array}{l}\text { Any underlying chronic health conditions like } \\
\text { HT, IHD, diabetes, chronic obstructive pulmo- } \\
\text { nary disease, congestive heart failure, chronic } \\
\text { kidney and liver disease, age > } 50 \text { years, immu- } \\
\text { nocompromising conditions? }\end{array}$ & 2 \\
\hline
\end{tabular}

Abbreviations: COVID-19, coronavirus disease 2019; HT, hypertension; ICU, intensive care unit; IHD, ischemic heart disease; LRI, lower respiratory infection.

Note: High risk - if 6 or more points; intermediate risk - if 2 to 4 points; low risk -0 points.

Source: Table adapted from the protocol of Department of Anaesthesiology, Sree Chitra Tirunal Institute for Medical Sciences and Technology, Trivandrum, India.

3. Negative pressure rooms are recommended for the management of COVID-19 cases. ${ }^{6,7}$

4. Intubation can be preferably done in negative pressure OT or in OTs with laminar flow through HEPA filter with increased air exchanges (>12 cycles/hours). Conventional AC to be switched off during AGP.

5. Limit the number of staff present in the OT during any aerosol generating procedures. ${ }^{2,3,5}$

6. A dedicated runner should be donned and wait outside the OT to procure and transport items if needed.

7. Early preparation of airway equipment and drugs should be done outside the dedicated room and shifted into the OT prior to the case. Each staff member should be aware of their assigned roles and the plan of anesthesia. ${ }^{7.8}$

8. As the PPE which can hamper the voice, clear and loud communication should be made. Closed-loop 
communication wherein the listener repeats instructions can reduce ambiguity and is integral in-patient safety.

9. Disposable covers (e.g., plastic sheets for surfaces, long ultrasound probe sheath covers, C-ARM covers for anesthesia machine) are used to reduce droplet and contact contamination of equipment. ${ }^{8}$

10. Stethoscope, marker pen, and disposable pen for writing notes should be placed in dedicated theater.

11. World Health Organization Surgical Safety Checklist must be followed in addition to the COVID-19 checklist.

12. Use of two high-efficiency particulate air (HEPA) viral filters. The first one should be interposed between Y-piece of the breathing circuit and the patient's mask or ETT. The second one should be placed between the expiratory limb and anesthesia machine. The gas sampling tubing should also be protected by a HEPA filter or should be scavenged. ${ }^{5,8,9}$

\section{Guidelines for Rationale Use of Personal Protective Equipment's}

1. Ensure HCW is not fasting and is well hydrated. They should ideally have used the restroom before donning. Remove nonessential items, jewelry, and phone. No gadgets should be carried to the theater., ${ }^{8,9}$

2. Before donning, proper hand hygiene should be ensured.

3. Centers for disease control (CDC) videos for donning and doffing personal protective $\mathrm{N}-95$ masks can be used for training the personnel. Appropriate fit is paramount and hence, a dedicated person to ensure fit testing is recommended. ${ }^{10}$

4. The institutional protocol for the rationale use of PPE is listed in - Table 2 .

\section{Reusing N-95 Mask}

1. For every suspected or confirmed case of COVID-19 infection or a patient, whenever an operative procedure is performed, the use of PPE is recommended by the CDC.

2. The National Institute for Occupational Safety and Health certified filtering facepiece respirator N95 should be used when performing procedures on such patients

3. Keeping in mind the impending supply depletion of the N-95 masks, we at our institution follow an extended use and reuse policy for the N-95 respirator in accordance with the $\mathrm{CDC}$ recommendations. ${ }^{10}$

4. Once doffing is done, the used respirators are hung in a dry area or placed in a breathable container with a name tag.

5. It can be sterilized by either one of the techniques. ${ }^{10}$

- 5-hour ethylene oxide cycle-one-hour chamber ethylene oxide exposure and 4-hour aeration.

- 1-hour cycle of gas plasma.

6. The same HCW should reuse the N-95 respirators and the number of reuse cycles is restricted to five. ${ }^{10}$

Table 2 Table enlisting the precautions to be taken and the suggested personal protection equipment's to be taken by health care workers

\begin{tabular}{|c|c|c|c|}
\hline No. & Risk category & Precautions & PPE \\
\hline 1 & $\begin{array}{l}\text { Aerosol/nonaerosol generating procedures in low risk/ } \\
\text { non- COVID-19 patients }\end{array}$ & Hand hygiene & $\begin{array}{l}\text { Cap } \\
\text { Triple layer mask } \\
\text { Gloves } \\
\text { Consider goggles }\end{array}$ \\
\hline 2 & Aerosol generating procedures in intermediate risk & Droplet and contact precautions & $\begin{array}{l}\text { Cap, gown, N-95 mask, goggles } \\
\text { and gloves }\end{array}$ \\
\hline 3 & Aerosol generating procedures in high risk & Droplet and contact precautions & $\begin{array}{l}\text { Full PPE (impermeable cap and } \\
\text { gown, N95 mask, goggles and } \\
\text { gloves) } \\
\text { Consider face shield }\end{array}$ \\
\hline 4 & Aerosol generating procedures in COVID-19 patient & $\begin{array}{l}\text { Airborne precautions } \\
\text { Droplet and contact precautions }\end{array}$ & Full PPE +face shield \\
\hline 5 & $\begin{array}{l}\text { Routine care/nonaerosol generating procedures of } \\
\text { COVID-19 patient }\end{array}$ & Droplet and contact precautions & Full PPE \\
\hline 6 & $\begin{array}{l}\text { Routine care/nonaerosol generating procedures in } \\
\text { high risk }\end{array}$ & Droplet and contact precautions & $\begin{array}{l}\text { Cap } \\
\text { N-95 mask } \\
\text { Gloves } \\
\text { Goggles }\end{array}$ \\
\hline 7 & $\begin{array}{l}\text { Routine care/nonaerosol generating procedures in } \\
\text { intermediate risk }\end{array}$ & $\begin{array}{l}\text { Hand hygiene and contact } \\
\text { precautions }\end{array}$ & $\begin{array}{l}\text { Cap } \\
\text { Triple layer mask } \\
\text { Gloves } \\
\text { Consider goggles }\end{array}$ \\
\hline
\end{tabular}

Abbreviations: COVID-19, coronavirus disease 2019; PPE, personal protective equipment.

Note: Table adapted from the protocol of Department of Anaesthesiology, Sree Chitra Tirunal Institute for Medical Sciences and Technology, Trivandrum, India. 


\section{Transfer of Patients into Operation Theater}

1. Patients should not be allowed to wait in the holding area and should be directly wheeled into the dedicated theater.

2. Whenever logistically possible, separate corridors should be used for transport to the OT. ${ }^{11}$

3. A team member should walk in advance of the patient to clear the way and hence to avoid OT traffic.

4. The patient should be reviewed and induced in the OT itself as a means of containment of infection to a single room.

5. A surgical mask or N-95 mask must be applied to the patient during transfer and till preoxygenation., ${ }^{2,11}$

6. When supplementary oxygen is needed, the oxygen mask must be applied over the surgical mask or N-95 mask. ${ }^{11}$

\section{Anesthetic Management}

1. List of Dos and Don'ts to reduce the incidence of aerosol generation in the perioperative period and ensure safety of HCWs is listed in - Table 3

2. As intubation results in significant exposure to a highviral load, it is a high-risk procedure. ${ }^{2,12}$

3. The goal is to secure the airway without contaminating the environment with aerosols.

Table 3 List of Dos and Don'ts to reduce the incidence of aerosol generation in the perioperative period and ensure safety of heath care workers

\begin{tabular}{|c|c|c|}
\hline No. & Dos & Don'ts \\
\hline 1 & $\begin{array}{l}\text { HEPA filter between tra- } \\
\text { cheal tube and breathing } \\
\text { circuit and another one } \\
\text { between expiratory limb } \\
\text { and ventilator }\end{array}$ & $\begin{array}{l}\text { High flow oxygen during } \\
\text { preoxygenation }\end{array}$ \\
\hline 2 & $\begin{array}{l}\text { Tight VICE grip with two } \\
\text { hands while holding mask }\end{array}$ & Bag and mask ventilation \\
\hline 3 & $\begin{array}{l}\text { Adequate muscle block- } \\
\text { ade before intubation }\end{array}$ & $\begin{array}{l}\text { Unnecessary ventilator } \\
\text { disconnections }\end{array}$ \\
\hline 4 & $\begin{array}{l}\text { Closed airway suction } \\
\text { system }\end{array}$ & Awake fiberoptic intubation \\
\hline 5 & $\begin{array}{l}\text { Lidocaine or dexmedeto- } \\
\text { midine prior to extubation } \\
\text { to avoid coughing and } \\
\text { bucking }\end{array}$ & Nebulization \\
\hline 6 & $\begin{array}{l}\text { During transfer with ETT } \\
\text { in situ, use AMBU with } \\
\text { HEPA filter. }\end{array}$ & $\begin{array}{l}\text { Routine use of supraglot- } \\
\text { tic airway devices unless } \\
\text { in unanticipated difficult } \\
\text { airway }\end{array}$ \\
\hline 7 & $\begin{array}{l}\text { Use of metered dose } \\
\text { inhalers if bronchodilators } \\
\text { are indicated }\end{array}$ & $\begin{array}{l}\text { Use of noninvasive ventila- } \\
\text { tors/ high flow nasal cannula } \\
\text { (to be used only in single } \\
\text { airborne isolation rooms } \\
\text { preferably with negative } \\
\text { pressure ventilation) }\end{array}$ \\
\hline
\end{tabular}

Abbreviations: COVID-19, coronavirus disease 2019; ETT, endotracheal tube; HEPA, high-efficiency particulate air.

Note: Table adapted from the protocol of Department of Anaesthesiology,

Sree Chitra Tirunal Institute for Medical Sciences and Technology,

Trivandrum, India.
4. Avoid AGP, including high-flow nasal oxygen, noninvasive ventilation, and bronchoscopy. ${ }^{11}$

5. Use of antisialagogues, for example, glycopyrrolate before induction can minimize the secretions and decrease contamination.

6. Acrylic aerosol shield box with armholes for unrestricted arm movement or transparent plastic sheet should be utilized to cover the face of the patient during intubation to prevent aerosol transmission. ${ }^{11,12}$

7. Awake intubation is best avoided in these scenarios since aerosol generation by coughing and atomization of local anesthesia has a high risk of disease transmission.

8. Once the patient is wheeled inside the OR, care should be taken not to remove the patient's mask till preoxygenation.

9. A thorough preoxygenation with two-person, twohanded mask holding with a VICE(VE) grip to improve the seal, for a duration of 3 to 5 minutes should prelude rapid sequence intubation. ${ }^{13}$

10. Since bag and mask ventilation are a high-risk procedure, rapid sequence intubation is routinely used at our center.

11. If at all bag mask ventilation is required, small tidal volumes should be used.

12. A video laryngoscope should be routinely preferred over direct laryngoscopy as the latter requires the anesthetist to be near the patient's airway. ${ }^{2,11,12}$

13. In a bid to reduce the number of intubation attempts, the most experienced anesthesiologist in the team should perform intubation.

14. An endotracheal tube (ETT) is preferred over a supraglottic airway because of decreased aerosolization risk.

15. Care must be taken not to contaminate surfaces with the used laryngoscope blade or suction catheter, and they should be contained in a disposable zip-lock cover and should be taken for decontamination.

16. Double gloves will enable one to shed the outer gloves after intubation and containment of the laryngoscope blade immediately postintubation.

17. Inflate the tracheal tube cuff to seal the airway before starting ventilation.

18. Tube position is confirmed by bilateral chest rise and the presence of continuous waveform capnography. Unnecessary contamination of stethoscope can be avoided, which can become a potential source of fomites.

19. When the nasogastric tube is required, it should be inserted under the plastic drape.

20. Use low gas flows and closed circuits throughout the case. ${ }^{2,3,12}$

21. Ensure tight connections at all interfaces between ETT and the ventilatory circuit and between the circuit and the machine.

22. Limit the ventilatory disconnections, and whenever it is required (e.g., during prone positioning), the ventilator is put on standby mode (to prevent the blast of the gas mixture) and ETT is clamped distal to HEPA filter at the end-expiratory phase. ${ }^{13,14}$

23. Whenever suctioning is required, a closed airway suction system is used to decrease viral aerosolization. 
24. Lung protective mechanical ventilation strategies are employed in the maintenance of ventilation throughout the procedure.

25. Like intubation protocol, aero shield box, or transparent plastic sheet should be used for extubation.

26. Whenever possible, extubation should be planned in the dedicated theater.

27. Adequate reversal for muscle relaxants should be administered to prevent respiratory distress and subsequent coughing.

28. Before extubation, application of nasal prongs with $<6 \mathrm{~L} / \mathrm{min}_{2}$ flow is advisable. ${ }^{12}$

29. Strong consideration should be given to pharmacological strategies for reduction of bucking on emergence from anesthesia (intravenous lignocaine or dexmedetomidine infusion can be used after clinical judgement).

30. Prophylactic antiemetic should be administered to reduce the risk of vomiting with subsequent contamination. ${ }^{12,13}$

31. Postextubation, surgical, or N-95 mask should be reapplied on the patient over which oxygen mask is placed.

32. The patient should be kept in the OT for postanesthesia care until full recovery.

33. If the patient is unfit for extubation, then the patient can be shifted to ICU with a single-use AMBU bag with an attached HEPA filter at the patient end. Transport ventilator is best avoided.

34. A separate team of personnel should be ready after proper donning to receive and transfer the patient from OT to ICU. ${ }^{14,15}$

35. Early and clear communication with the ICU staff about patient transfer should be made for ensuring robust preparedness to receive patient.

\section{Potential Drug Interactions}

1. Lopinavir and ritonavir that are used in COVID-19 patients can increase the plasma concentration of midazolam and fentanyl potentiating respiratory depression. When taken along with warfarin and rivaroxaban, it can increase the risk of bleeding. ${ }^{2,3}$

2. Chloroquine, one of the agents used as a part of treatment regimen and prophylaxis against COVID-19, is known to cause QT prolongation. Hence, anesthetic agents like sevoflurane and ondansetron should be used with caution as they could precipitate torsades de pointes. ${ }^{2,12,13}$

\section{Decontamination of Operation Theater}

1. All unused items on the drug tray should be assumed as contaminated and should be discarded.

2. Discard disposable equipment safely after single patient use (breathing circuit, mask, tracheal tube, HEPA filters, gas sampling line, and soda-lime). Water trap must be changed if it becomes potentially contaminated.

3. Decontaminate reusable equipment fully and according to manufacturer's instructions. ${ }^{14}$
4. Seal all used airway equipment and suction catheter in a double zip-lock bag which must then be removed for decontamination and disinfection.

5. A minimum of 1 hour is planned between cases to give adequate time for thorough decontamination of all surfaces, screens, keyboard, cables, monitors, and anesthesia machine with 2 to $3 \%$ hydrogen peroxide spray disinfection, 2 to $5 \mathrm{~g} / \mathrm{l}$ chlorine disinfectant, or $75 \%$ alcohol wiping of solid surfaces of the equipment and floor. ${ }^{14,15}$

6. The hydrogen peroxide vaporizer is used to decontaminate the OT with the negative pressure ventilation system..$^{14,15}$

\section{Conclusion}

The best defense against any outbreak is a robust health system. Anesthetists and other HCWs who will be on frontlines during the management of this pandemic should have thorough knowledge, utmost vigilance, and clear strategy for the effective execution of the infection control policies to minimize disease transmission. In this background, this comprehensive article deals with the perioperative management during this pandemic and includes risk stratification based on an innovative simple scoring system, rationale use of PPE, and infection prevention protocols. The document of updated literature, though not intended to replace any guidelines, is aimed at providing protocol to HCWs to protect themselves while providing the best care in this pandemic.

\section{Funding}

None.

\section{Conflict of Interest}

None declared.

\section{References}

1 Global surveillance for COVID-19 caused by human infection with COVID-19 virus Interim guidance WHO. 2020 Available at: https://apps.who.int/iris/handle/10665/331506. Accessed May 4, 2020

2 Coronavirus - guidance for anaesthesia and perioperative care providers. Available at:https://www.wfsahq.org/resources/ coronavirus Accessed May 4, 2020

3 American Society of Anesthesiologists. Available at: https:// www.asa.org.au/wordpress/wp-content/uploads/News/eNews/ covid-19/ASA-summary-of-anaesthesia-management.pdf Accessed May 4, 2020

4 World Health Organization. Available at: https://www.who.int/ emergencies/diseases/novel-coronavirus-2019/technicalguidance/infection-prevention-and-control. Accessed May 4, 2020

5 Malhotra N, Joshi M, Datta R, Bajwa SJ, Mehdiratta L. Indian Society of Anaesthesiologists Advisory and Position Statement regarding COVID-19. Indian J Anaesth 2020;64:259-263

6 Evaluating and Testing Persons for Coronavirus Disease. 2019 (COVID-19); Centers for disease control and prevention. Available at: https://www.cdc.gov/coronavirus/2019-ncov/ hcp/clinical-criteria.html Accessed May 4, 2020

7 Wong DT, Kamming D, Salenieks ME, Go K, Kohm C, Chung F. Preadmission anesthesia consultation using 
telemedicine technology: a pilot study. Anesthesiology 2004;100(6):1605-1607

8 John R. Greenland. COVID-19 infection implications for perioperative and critical care physicians. Anesthesiology 2020

9 Rational use of personal protective equipment for coronavirus disease (COVID-19) Interim guidance 19 March 2020. 2020 Available at: https://apps.who.int/iris/handle/10665/ 331498Accessed May 4, 2020

10 Centers for Disease Control and Prevention. Available at: https:// www.cdc.gov/coronavirus/2019-ncov/infection-control/ control recommendations.html Accessed May 4, 2020

11 WongJ, YuanQG. Preparing for a COVID-19 pandemic: a review of operating room outbreak response measures in a large tertiary hospital in Singapore. Can J Anesth 2020. Available at: https://link.springer.com/article/10.1007/s12630-020-01620-9. Accessed May 4, 2020
12 Cook TM, El-Boghdadly K, McGuire B, McNarry AF, Patel A, Higgs $A$. Consensus guidelines for managing the airway in patients with COVID-19. Anaesthesia 2020. Doi: 10.1111/anae. 15054

13 Meng L, Qiu H, Wan L, et al. Intubation and ventilation amid the COVID-19 outbreak: Wuhan's experience. Anesthesiology 2020. Doi:10.1097/ALN.0000000000003296

14 Brindle M, Gawande A, Managing COVID-19 in surgical systems. Ann Surg. 2020 doi:10.1097/SLA.0000000000003923

15 TangG, KamA. Perioperative management of suspected/ confirmed cases of COVID-19. 2020 Available at: https://www. wfsahq.org/components/com_virtual_library/media/1c4ec5c64b9aaacf7c47f76a61fb6edc-atow-422-01.pdf. Accessed May 4, 2020 